\title{
Looking through a social lens: conceptualising social aspects of knowledge management for global health practitioners
}

\author{
Rupali J. Limaye, ${ }^{1}$ Tara M. Sullivan, ${ }^{1}$ Scott Dalessandro, ${ }^{1}$ Ann Hendrix-Jenkins ${ }^{2}$ \\ 1 Johns Hopkins Center for Communication Programs, Baltimore, MD; ${ }^{2}$ FHI 360, Washington, D.C., USA
}

\begin{abstract}
Significance for public health
Managing knowledge is essential for improving population health outcomes. Global health practitioners at all levels of the health system are bombarded with information related to best practices and guideline changes, among other relevant information to provide the best quality of care. Knowledge management, or the act of effectively using knowledge, has yet to capitalize on the power of social connections within the context of global health. While social elements have been incorporated into knowledge management activities, we suggest that systematically integrating key concepts that leverage social connections, such as social systems, social capital, social learning, and social software, will yield greater benefit with regard to health outcomes. As such, we outline a new conceptualization of knowledge management, focusing on the social aspects of the practice, and posit that such an approach can further the impact of global health interventions and is crucial for global health practitioners.
\end{abstract}

\begin{abstract}
Knowledge management plays a critical role in global health. Global health practitioners require knowledge in every aspect of their jobs, and in resource-scarce contexts, practitioners must be able to rely on a knowledge management system to access the latest research and practice to ensure the highest quality of care. However, we suggest that there is a gap in the way knowledge management is primarily utilized in global health, namely, the systematic incorporation of human and social factors. In this paper, we briefly outline the evolution of knowledge management and then propose a conceptualization of knowledge management that incorporates human and social factors for use within a global health context. Our conceptualization of social knowledge management recognizes the importance of social capital, social learning, social software and platforms, and social networks, all within the context of a larger social system and driven by social benefit. We then outline the limitations and discuss future directions of our conceptualization, and suggest how this new conceptualization is essential for any global health practitioner in the business of managing knowledge.
\end{abstract}

\section{Introduction}

Information refers to data that is organized and has a purpose. ${ }^{1}$ In contrast, knowledge entails more complex human engagement by transforming information into a combination of experience, values, contextual information, and personal insight that provides a framework for incorporating new information and experiences. ${ }^{2}$ Knowledge management, loosely defined as the process of capturing, distributing, and effectively using knowledge, ${ }^{3}$ has emerged as an important strategy for global health. ${ }^{4}$ Within the context of global health challenges, knowledge management practices have established importance in enhancing the exchange and flow of the latest information. ${ }^{5}$

Knowledge management practices provide an opportunity for improvement in health care. ${ }^{6}$ Healthcare delivery is a complex process that occurs through systems involving a range of healthcare providers. ${ }^{7}$ Yet, health care professionals have been characterized as individuals who may have access to a vast amount of information but are unable to locate what they need and operationalize this information when the opportunity arises. ${ }^{8}$ In reality, there are numerous barriers health care providers face in making and acting on evidence-informed decision-making, including: difficulty in keeping current with the latest peer-reviewed literature; difficulty in accessing available evidence; and difficulty in locating information specific enough for their highly specific time and place. ${ }^{9}$

In the context of global health care delivery, the scope of designing and implementing knowledge management interventions is challenging given the great depth and breadth of global health systems. ${ }^{10}$ In today's information-rich environment, many global health practitioners have access to almost any data, information and/or knowledge they require for their job and have a wide range of knowledge needs, in a variety of conditions and settings, at different times. ${ }^{11,12}$ However, in order to be able to find and utilize the most relevant knowledge, individuals must possess the appropriate capacity and agency to use knowledge management tools and tap known networks. ${ }^{13}$ Without proper awareness of existing networks and training in the use of available tools, individuals may not be able to zero in on the information they require and are thus uncertain about their decision-making process because they are unable to translate the information into actionable knowledge. ${ }^{14}$ At the same time, significant numbers of health service providers around the world have little means to access quality health knowledge including current practice, highlighting the importance of digital access and inclusion. ${ }^{15}$

To meet the health information needs of global health practitioners, creating strategic connections between knowledge sources is paramount in order for audiences to reap the benefits across existing products and platforms, to tap new networks, and to increase engagement and generate multidirectional flows to inform reach and value. ${ }^{16}$ The human and social variables needed to affect global health in positive ways are as complex as humanity itself. ${ }^{17}$ If unrecognized, let alone unexplored by the field of knowledge management, a great part of what makes the world turn is missed.

Today's global health challenges and needs are complex: they are persistent and global while also critical and local. National and international health system standards continue to emerge and shift, and health care providers are expected to understand, adapt, and implement new guidelines continually. This reality requires significant coordination among relevant sectors such as health, environ- 
ment, and education, development champions, and actors, both public and private. At the same time, global health needs are precise; many times felt most in places where human resources are limited, where beneficiaries and supplies are hardest to reach, and where quality knowledge - and even the more basic element of information - are scarce or unavailable to those who need it to play their part in achieving global health objectives. Ultimately, achieving both individual and collective performance success requires that knowledge be shared, brokered, and thoughtfully managed throughout highly diverse and distributed global health care delivery systems.

In this paper, we propose a special focus on the social aspects of knowledge management in a global health context, which highlights an extremely powerful aspect of knowledge management that has the potential to contribute to successful performance. In proposing this conceptualization, it is important to note that we do not assert that knowledge management has only recently been rooted in social systems or includes social elements. To the contrary, we acknowledge that theories and practices of knowledge and its management are firmly rooted in social contexts. Instead, we assert that by paying attention to social aspects of knowledge management, we can accelerate the process of getting research into practice, and thus specifically contributing to the social benefits of global health - reduced morbidity and mortality. This conceptualization that examines the important social factors of knowledge management is systematically built on specific social concepts, including social systems, social capital, social learning, and social software working together to achieve social benefit outcomes. We first briefly outline the evolution of knowledge management, then outline the concepts underlying social knowledge management, and end with a discussion focused on next steps related to our conceptualization of social knowledge management.

\section{Evolution of knowledge management: a brief history}

Although the characterization of knowledge management as a discipline in global health is a relatively new phenomenon, practical needs for knowledge management have been present for millennia, and the knowledge management field is rooted in religion, philosophy, psychology, economics, and business theory. ${ }^{18}$ Over the last three decades however, primarily for-profit businesses have transformed knowledge management into a discipline that weaves people, processes, and technology together so that the knowledge necessary for an organization to succeed is captured, created, shared, and leveraged for maximum benefit. ${ }^{19}$ While many elements of knowledge management have remained consistent, the field has shifted emphasis over the last 30 years yielding distinct generations of knowledge management that are briefly summarized below.

\section{First generation knowledge management: focusing on technology and codification for increasing efficiency in the private sector}

First generation knowledge management focused on technology, codification, and maximizing efficiency and its use was primarily in the information technology [IT] sector. Much of this era sought to provide access to explicit knowledge [knowledge that is codified] through data warehousing, document management, and data mining. ${ }^{20} \mathrm{~A}$ survey of knowledge management papers published from 1990-2000 revealed that more than $40 \%$ were written by and for computer or IS/IT professionals. ${ }^{21}$ Knowledge management in this generation was primarily focused on extracting explicit knowledge from people and organizing it within an electronic repository, providing many an opportunity to search for and retrieve codified knowledge. ${ }^{22}$

This technology and codification-focused approached was intended to increase efficiency and make use of knowledge already existing within organizations, mostly within the private sector. ${ }^{23-25}$

\section{Second generation knowledge management: shifting from technology to human interaction and building knowledge capacity}

Second generation knowledge management moved the focus to the interaction between learning and technology use. Originally, as technology applications became accessible and facilitated interaction, the role of IT grew within knowledge management, namely to provide capabilities for finding and obtaining information. ${ }^{26}$ However, scholars began to recognize that despite its ability within many companies to successfully leverage knowledge in many ways, technology alone was not able to deliver comprehensive knowledge management. ${ }^{27}$ In response to these limitations, numerous knowledge management strategies developed during this second generation shifted away from databases and repositories to a new focus on learning. ${ }^{28}$

Within this generation, many scholars began to examine the role of organizational culture on knowledge management. Evidence suggested that organizational values and leadership play key roles in the facilitation and utilization of knowledge management, ${ }^{29}$ and several scholars articulated that organizational culture is the most significant barrier to effective knowledge management. ${ }^{30,31}$

\section{Third generation knowledge management: focusing on people, collaboration, and cooperation}

Today, knowledge management has shifted to knowledge management practices far more interested in fundamentally peoplefocused approaches to capturing and sharing knowledge with the aim of putting knowledge into action. Methods include after-action reviews, peer assists, and knowledge cafés as a means to increase knowledge exchange in face-to-face settings. ${ }^{32}$ Within the first and second generations, much of the literature on knowledge management was dominated by the utilization of IT-focused research, and centred on how technologies could facilitate the acquisition, codification, and exploitation of knowledge. ${ }^{33}$ As a result, peoplefocused perspectives represent a very small proportion of knowledge management inquiry, and there is relatively less information regarding its utilization. ${ }^{34}$ However, in changing and increasingly globalized settings where interactions span geographical areas, languages, and technical topics, many indicate that knowledge management must evolve to deal directly with how people and organizations create and utilize knowledge and understanding know-how - in their daily work lives to analyse situations, make decisions, execute actions, ${ }^{35}$ and pursue further inquiry to explore the most effective approaches.

While approaches and paradigms representing the knowledge management state of the art have shifted and widened through the three knowledge management generations, a large proportion of knowledge management continues to draw upon a select set of knowledge management theories as frameworks for developing and implementing knowledge management systems. These widelyused theories include: the D-I-K-W Pyramid, ${ }^{36}$ the knowledge management Maturity Model, ${ }^{37}$ and Nonaka's Spiral Model. ${ }^{38}$ While each of these provides an excellent contribution to knowl- 
edge management, from a global health perspective, these paradigms are limited. These models make an important contribution to the literature and to our understanding of knowledge processes but do not sufficiently address the scale and complexity of work concerned with improving social benefits, nor do they speak to the importance and richness of the social tapestry underlying global health work. We suggest that the prominent knowledge management discourse pays insufficient attention to human and social factors. Because knowledge is inextricably intertwined with human cognition, and is created, used, and shared in ways that is tied to the social context of one's social system, ${ }^{39}$ not recognizing the role that one's social context plays in knowledge management is short-sighted. In fact, it is the interaction between knowledge management processes, technology, and people that provide global health practitioners with the opportunity to manage knowledge effectively. ${ }^{40}$

\section{Leveraging social aspects of knowledge management}

As we view human and social factors as critical to effective global health knowledge management work, we propose a conceptualization of knowledge management which highlights the social aspects of knowledge management: occurring within social systems, within the context of social interaction, which includes social networks, social learning, social capital, and social software and platforms, and driven by social benefit. We suggest that these social aspects underlie and guide knowledge management, such as the processes to generate, capture, synthesize, exchange and use knowledge; technology to support knowledge management interventions; organizational systems to support a culture of knowledge management; and key relationships that facilitate exchange and knowledge use.

Figure 1 illustrates these social aspects of knowledge management. Social systems provide a context for knowledge management practice, where members of a social system are bound together by a common objective. Successful knowledge management and exchange is mediated through factors related to social capital, social networks, and social learning. Social capital is the combination of resources derived from networks possessed by an individual or social unit. Social networks, which are a dimension of social capital, refer to structures that individuals tap into to exchange information and knowledge. Social capital, with its structural (social networks), relational (identification, norms, reciprocity, and trust), and cognitive (shared vision and language) dimensions, influences intermediate outcomes by increasing knowledge quality and quantity, and improving cooperation and coordination. Social learning theory focuses on learning as it takes place in a social context. Both self- and collective-efficacy relate to beliefs in capability to attain goals and accomplish desired tasks, noting that perceptions vary by the tasks at hand and other contextual factors. As with social capital, the status of social learning measures can enhance or inhibit knowledge management effectiveness. While social learning is not inherently focused on social benefit outcomes, efficacy beliefs influence the courses of action people choose to pursue and thus are a key determinant in the creation of new intellectual capital and support cooperation. Managing knowledge in a global context is challenging because individuals and organizations are geographically dispersed. Social software provides a means for extending the reach and exchange of knowledge by connecting collaborators so they can socially interact, exchange and create knowledge, and network. In the case of knowledge management for health and development, members are bound together by the goal of improving social benefits, ultimately reducing morbidity and mortality.

Regarding our chosen factors, recent scholars have recognized the importance of social factors in knowledge sharing contexts and this aided us in determining which factors are most relevant. For example, Chiu et al. looked at social capital and social cognitive theory to better understand knowledge sharing in the context of online communities (social software and platforms), arguing that aspects of social capital (e.g., social interaction ties, trust, norm of reciprocity, identification, shared vision and shared language) and outcomes expectations influence knowledge sharing. ${ }^{41}$ Nahapiet and Ghoshal examined how social capital factors facilitate the creation of intellectual capital. ${ }^{42}$ Inkpen and Tsang examined the role of key social capital factors (structural, cognitive, and relational), ${ }^{43}$ and articulate how these factors differentially influence knowledge transfer across three types of business networks (intra-corporate network, strategic alliance, industrial district). Mauer et al. ${ }^{44}$ studied social capital factors of number of intra-organizational ties, tie

SOCIAL SYSTEMS
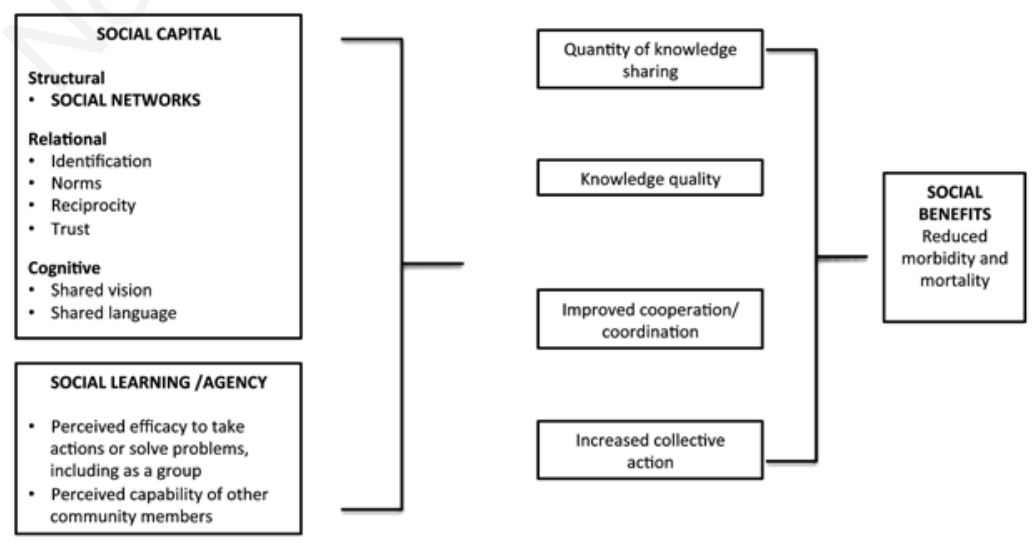

SOCIAL SOFTWARE

Figure 1. Social aspects of knowledge management. 
strength, and trust, hypothesizing that these factors would increase knowledge transfer, which in turn would improve organizational performance. While these studies elucidate relevant social aspects that contribute to knowledge management, explorations into how social aspects have systematically been incorporated, implemented, and evaluated within global health knowledge management programs are, to our knowledge, limited.

\section{Concepts underlying social aspects of knowledge management}

Now that we have outlined our conceptualization of which social aspects should be systematically incorporated into knowledge management approaches, we will now further explore each social aspect and discuss how it can benefit knowledge management approaches in the global health setting.

\section{Social systems: a context for knowledge management practice in global health}

All of the social aspects of knowledge management in our conceptualization take place within a social system, a set of interrelated units engaged in joint problem solving to accomplish a common goal. ${ }^{45}$ Units or members of a social system range from individuals to organizations or subsystems and are bound together by a common objective. Diffusion of knowledge within a system may be impeded or accelerated based on the social and communication structure of the system, system norms, the role and influence of opinion leaders and change agents, the type of innovation-decision (optional, collective, or authority) and consequences of innovations. ${ }^{45}$ As we seek to systematically incorporate social aspects into knowledge management approaches in global health programming, we must be mindful of factors that can facilitate social benefits while working within multiple social systems. Knowledge management in the context of global health takes place in an essentially social system - where health practitioners are functioning to achieve a common set of health goals - improving health services, supporting healthier client behaviours, and decreasing morbidity and mortality rates.

\section{Social capital: essential for effective collective action}

Social capital is conceptualized as resources within a social structure that are utilized for purposive action, and by definition, includes resources, accessibility, and use. The theory behind the concept suggests that social capital is dependent upon a social network and that certain positions within that network affect how social capital is accessed. ${ }^{46,47}$ In addition, valued resources in most social structures are represented by wealth, power and status. ${ }^{48}$ Therefore, the concept is embedded within social relations within a network. ${ }^{49}$ Social knowledge management relies on networks, norms, and trust, making social capital an essential component for health professionals cooperating with one another for a mutual benefit. Social capital includes features of a social organization that facilitate coordination and cooperation for mutual benefit, including networks, norms and trust. ${ }^{50}$ Social capital is a multidimensional concept that includes structural, cognitive, and relational aspects. The structural dimension relates to access to other actors, the cognitive dimension includes shared vision and shared language, and the relational dimension includes trust, identification, reciprocity and norms. ${ }^{42}$

Given the importance of social determinants of health, international public health researchers and practitioners have examined the link between social capital and health. In the context of knowledge management, researchers have hypothesized and measured the link between dimensions of social capital (structural, cognitive, and relational) and knowledge quality and quantity of knowledge sharing and found that social interaction ties, reciprocity, and identification increased individuals' quantity of knowledge sharing. ${ }^{41}$

However, while research has been conducted in lower- and middle-income settings on the relationship between social capital and health and on the relationship between social capital and knowledge management factors in the organizational context in developed countries, there is very little research on the role of social capital and knowledge management outcomes in the context of global health programs. Yet, as previously stated, global health work requires coordinated efforts to achieve social benefit goals such as decreased morbidity and mortality. The concept of social capital recognizes that the social networks, trust, and norms have value and can facilitate or hinder the progress of collective action toward global health goals, and as a result, we consider it a key social aspect of knowledge management.

\section{Social networks: leveraged to rapidly diffuse knowledge}

Social network theory has made major contributions to understanding human social organization. ${ }^{51}$ Originating in mathematical graph theory, network theory has been used to address populationlevel problems by examining individual-level interactions within a social system. ${ }^{52}$ It was developed as a response to traditional individualistic social theory, which ignored the social context of a given actor within a given situation. ${ }^{53}$ From a knowledge management perspective, social network theory posits that individuals share knowledge among their networks to create organizational knowledge. ${ }^{54}$ To maximize knowledge sharing, health professionals need to be able to tap into personal and professional social networks. For health professionals, knowledge generation, sharing, and transfer occur within a network, which provide opportunities to discuss ideas and gain feedback. Global public health evidence changes at an increasingly rapid rate, and as a result, guidelines regarding health care are constantly being revised. Social aspects of knowledge management recognize that the influence of key individuals and organizations within networks to diffuse the most relevant and recent information and knowledge. As knowledge generation, sharing and transfer require collaboration, sharing and transfer of knowledge is dependent on the personal network of each individual within a social system. ${ }^{55}$ Networks amongst healthcare professionals are nothing new, and have long played a critical role in healthcare delivery; however, an examination of their potential for knowledge sharing is relatively new. ${ }^{7}$ From a global health perspective, knowledge exchange through communities of practice and informal social networks has the potential to improve knowledge management in global health issues. The utilization of communities of practice (CoPs), or a group of people who decide to deepen their knowledge and expertise in a particular topic on an on-going basis is increasing in global health. Over the last few years, several CoPs have been launched in topics related to international health. Lessons learned from these nascent CoPs indicate that working together with a common vision and knowledge basis and exchanging views with peers on technical issues are powerful ways to transfer operational and tacit knowledge for better program implementation. ${ }^{56} \mathrm{CoPs}$ also perform several roles that facilitate the conduct, implementation and utilization of research to improve health care practice and accountability and are important tools for global health professionals in lower and middle-income countries because they are a cost-effective way to deliver capacity building assistance and training. ${ }^{56}$ 


\section{Social learning: applied to increase capacity}

Many theories have been developed to explain human behaviour, and specifically, how learning from others affects individual behaviour. Social learning theory was developed to primarily acquire insight into the underlying impulses of behaviour, taking into account not only internal forces, but also taking into account external, or social, forces. ${ }^{57}$ The theory was developed to highlight the importance of social agents as a source of behavioural patterns, as these social factors were largely ignored in the early literature related to behavioural theory. ${ }^{58}$

Health professionals' behaviours are influenced by personal and social factors. For example, an important determinant of a provider's counselling behaviour is how his or her colleagues counsel their patients. ${ }^{59}$ Similarly, doctors learn and remain up-todate on surgery practices and techniques by observing more experienced doctors conduct surgery. ${ }^{60}$ In this way, health professionals learn from other, more experienced colleagues, how to do their work. This type of learning is called social learning. Social cognitive theory defines human behaviour as dynamic - consisting of reciprocal interaction of behaviour, personal factors, and social factors, and individual behaviour is shaped by social system and cognition, including expectations and beliefs. Social learning refers to the idea that people learn from one another through observation, imitation, and modelling. ${ }^{58}$ From a knowledge management perspective, individuals do not tap into knowledge management systems simply to seek information or knowledge, but rather, they engage in knowledge management systems to meet other likeindividuals, seek support, and develop a sense of identity.

In global health, social learning is particularly important in non-virtual settings. Specifically related to the global health context, much of individual knowledge is intangible and encompassed in the stories people tell. ${ }^{61}$ Storytelling does not replace practical or analytical thinking; rather, it supplements these types of knowledge by enabling participants to hear and understand new perspectives. Tacit knowledge is difficult to articulate in writing and is mostly gained through personal experience, and therefore, a person-to-person approach is most effective for tacit knowledge sharing. Studies indicate that higher levels of tacit knowledge can be exchanged through person-to-person learning approaches compared to virtual approaches. ${ }^{62}$ For example, people-focused approaches, such as peer assists, promote a nurturing environment where one group can learn from another and as a result, capacity is built, and are an effective way to share tacit knowledge, which is the objective of a knowledge café, or an approach that brings together a group of people who have a common interest and will benefit from learning from each other related to that common interest. One way to encourage and foster social learning in public health is through the creation of interpretive forums and events that allow for interpretation of complex problems or data. ${ }^{63}$

\section{Social software and platforms: used to expand knowl- edge reach and exchange}

In contexts where the evidence and guidelines for health service provision are constantly changing, an effective and efficient way for relatively isolated health workers to stay up-to-date is through technological means. ${ }^{64}$ With the emergence of Web 2.0, also known as the social web, social software and platforms allows users to be both consumers and producers of information and supports group interaction, social networking, and communities. ${ }^{65}$ Examples of social software and applications include: wikis, blogs, podcasts, video streaming, social bookmarking, RSS feeds, social networking services, instant messaging, virtual meetings, and online social gaming. ${ }^{65}$ Recent research indicates that social media tools create a dynamic infrastructure that facilitates faster, easier and more widespread information sharing, but perhaps even more powerfully, rapid and higher-order knowledge management, specifically knowledge transfer, translation and transformation. ${ }^{66}$ Within the context of global health specifically, social software and platforms facilitate knowledge management by reducing reliance on formal structures and resulting bottlenecks, and supports faster collection and refinement of data, decision-making and more complete knowledge resources, as evidenced by the reliance of social media in global health emergency contexts. ${ }^{67}$ While social software and platforms offer promising new ways to exchange knowledge, issues to consider in their use include the shear volume of data and information conveyed through these platforms, the high speed in which new content created and posted, the wide variety of sources, and the varying quality of information. ${ }^{68,69}$ Although developed separately from knowledge management, social software and platforms are now increasingly being recognized as invaluable for sharing and exchange, notably due to the format of breaking knowledge into small chunks that flow easily, and can be assessed for patterns from many perspectives, thus creating order from chaos. ${ }^{67}$ We suggest that social software and platforms is a critical concept underlining the aspects of social knowledge management because it enables a bottom-up knowledge management approach, based on mass input into what is shared, in contrast to more traditional knowledge management approaches where a topdown approach is employed as a means of dissemination. ${ }^{70}$

\section{Social benefit: the importance of social aspects of knowledge management for societal good}

From our social knowledge management perspective, knowledge is created, shared, transferred, and synthesized with the aim to benefit not only individual people and organizations, but also the larger society - thus conveying a social benefit. In global health, knowledge management supports outcomes, where our primary goal is improving health. As a result, we view the use of knowledge management principles and practices from public good perspective - that in which knowledge management is used for social benefit.

\section{Discussion}

In a highly networked environment where achieving collective impact requires input and cooperation from an extremely diverse cast of actors, social aspects of knowledge management must also be sensitive to the values of those actors. Beyond geographic, demographic, and experiential differences, the underlying motivations of stakeholders in global health are diverse and need to be understood as critical variables. ${ }^{71}$ In order to address common challenges such as meeting unmet demand for contraceptives, knowledge management interventions that emphasis social aspects must include diverse perspectives. For individuals and organizations representing rights, health, environmental, and limited resource perspectives, fostering trust is a fundamental component of our conceptualization, as are neutral brokers who can help facilitate knowledge exchange and ensure that diverse values represented in knowledge management systems and approaches. ${ }^{72}$

We must reiterate that our conceptualization does not suggest that social aspects have not been incorporated within knowledge management for global health. We simply suggest that the ideas behind the social concepts we outline have not been systematically incorporated into knowledge management approaches within the context of global health. We also suggest that by doing so, knowl- 
edge management has the potential to have greater impact on health outcomes.

Ultimately, incorporating social aspects into knowledge management requires an iterative and adaptive approach, where knowledge management interventions are built on an implementation science framework that focuses on measurement and learning before, during and after implementation, through a careful and deliberate approach that utilizes the social aspects we outline in this paper. This approach includes feedback loops that allow for iterative improvements that are responsive to stakeholders' needs, preferences, and values, thus ensuring highly resonant and effective efforts. We also recognize that this approach requires training to ensure that global health practitioners are adequately tapping into the various resources available to them through this conceptualization. We have begun to provide training to global health practitioners in our conceptualization within the East African and Caribbean regions, and are currently evaluating our efforts.

\section{Social aspects of knowledge management: limitations}

Many of the social aspects we suggest as essential to knowledge management are drawn from other theories, models and concepts utilized within the field of global public health. These aspects include social learning theory, diffusion of innovations, social network analysis, and social capital. Although each shows promise in enhancing positive health outcomes, to our knowledge, there is not yet evidence of the effect of their cumulative impact within the context of a knowledge management intervention.

\section{Conclusions}

As the fields of knowledge management and global health continue to evolve to respond to the needs of an ever-changing world, we suggest that careful attention be paid to critical pieces that enhance knowledge management efforts, which in turn impact the social and intellectual capital within, across, and between many actors, donors, and governments. The social context in which we work requires us to be cognizant of and reactive to the human dynamics that lie at the centre of an improved model of knowledge management.

Correspondence: Rupali J. Limaye, Johns Hopkins Center for Communication Programs, 111 Market Place, Suite 310, Baltimore, MD 21202, USA.

Tel.: +1.202.294.5412 - Fax: +1.410.659.6266.

E-mail: rlimaye@jhsph.edu

Key words: Social capital; Social networks; Social media; Social learning; Knowledge management.

Contributions: RJL, TMS, developed and refined the concept, directed the writing of the manuscript, and wrote several sections of the manuscript; SD, AHJ, drafted sections of the manuscript.

Conflicts of interest: the authors declare no potential conflict of interest.

Received for publication: 2 November 2016.

Accepted for publication: 24 January 2017.

(C) Copyright R.J. Limaye et al., 2017

Licensee PAGEPress, Italy

Journal of Public Health Research 2017;6:761

doi:10.4081/jphr.2017.761

This work is licensed under a Creative Commons Attribution NonCommercial 4.0 License (CC BY-NC 4.0).

\section{References}

1. Ahenkorah-Marfo M. Clarifying concepts of knowledge and information: literature review. J Knowledge Management Practice 2012;13.

2. Davenport TH, Prusak L. Working knowledge: how organizations manage what they know. Harvard Business Press; 1998.

3. Davenport TH. Saving IT's soul: human-centered information management. Harvard Business Rev 1994;72:119-31.

4. Ferguson JE, Cummings S. Knowledge management in practice. The case of international development. In: Koohang A, Harman $\mathrm{K}$, Britz J, eds. Knowledge management: research and application. 2008. p. 75-112.

5. Quinn E, Huckel-Schneider C, Campbell D, et al. How can knowledge exchange portals assist in knowledge management for evidence-informed decision making in public health? BMC Public Health 2014;14:443.

6. Nilakanta S, Miller L, Peer A, Bojja VM. Contribution of knowledge and knowledge management capablity on business processes among healthcare organizations. Hawaii: System Sciences; 2009.

7. Bordoloi P, Islam N. Knowledge management practices and healthcare delivery: a contingency framework. Electronic J Knowledge Manag 2012;10:110-20.

8. Gray JA, de Lusignan S. National electronic library for health. $\mathrm{Br}$ Med J 1999;319:1476.

9. LaPelle NR, Luckmann R, Hatheway Simpson E, Martin ER. Identifying strategies to improve access to credible and relevant information for public health professionals: a qualitative study. BMC Public Health 2006;8:89-101.

10. Kaul I, Faust M. Global public goods and health: taking the agenda forward. Bull World Health Organ 2001;79:869-74.

11. Owen JM. Knowledge management and the information professional. Information Serv Use 1999;19:7-16.

12. Binney D. The knowledge management spectrum-understanding the KM landscape. J Knowledge Manag 2001;5:33-42.

13. Omotayo FO. Knowledge management as an important tool in organisational management: a review of literature. Library Philosophy Practice 2015:1.

14. Kuo Y, Ye K. How employees' perception of information technology application and their knowledge management capacity influence organisational performance. Behav Informat Technol 2007;29:287-303.

15. Godlee F, Parkenham-Walsh N, Ncayiyana D, et al. Can we achieve health information for all by 2015? Lancet 2004;364:295-300.

16. Zack MH. Developing a knowledge strategy. California Management Rev 1999;41:125-45.

17. Marmot M. Social determinants of health inequalities. Lancet 2005;365:1099-104.

18. Wiig KM. Knowledge management: an emerging discipline rooted in a long history. In: Despres C, Chauvel D, eds. Knowledge horizons: the present and the promise of knowledge management. Abingdon-on-Thames, Routledge; 2000. pp 3-26.

19 Guptill J. Knowledge management in health care. J Health Care Finance 2005;31:10-4.

20. McElroy MW. Second-generation KM: a white paper. Emerg J Complex Issues Organizat Manage 2000;2:90-100.

21. Scarborough H, Swan J, Preston J. Knowledge management-the next fad to forget people. In: Proceedings of European Conference on Information Systems, Copenhagen 1999.

22. Hansen MT, Nohria N, Tierney T. What's your strategy for managing knowledge? The knowledge management yearbook 20002001. 1999;1:55-69. 
23. Horton D, Thiele G, Oros R, et al. Knowledge management for pro-poor innovation: the Papa Andina case. Knowledge Manage Dev J 2011;7:65-83.

26. Alavi M, Leidner DE. Review: knowledge management and knowledge management systems: conceptual foundations and research issues. MIS Quart 2001:107-36.

27. McDermott R. Why information technology inspired but cannot deliver knowledge management. California Manage Rev 1999;41:103-17.

28. Hiebeler RJ. Benchmarking: knowledge management. Planning Rev 1996;24:22-9.

29. Alavi M, Kayworth TR, Leidner DE. An empirical examination of the influence of organizational culture on knowledge management practices. J Manag Informat Syst 2005;22:191-224.

30. Davenport TH, De Long DW, Beers MC. Successful knowledge management projects. MIT Sloan Manag Rev 1998;39:43.

31. Davenport TH, Klahr P. Managing customer support knowledge. California Manage Rev 1998;40:195-208.

32. Gurteen D. Leading issues in social knowledge management. Sonning Common: Academic Conferences and Publishing Limited; 2012.

33. Scarborough H, Swan J, Preston J. Knowledge management-the next fad to forget people. In: Proceedings of European Conference on Information Systems, Copenhagen 1999.

34. Aramburu N, Sáenz J. Promoting people-focused knowledge management: the case of IDOM. J Knowledge Manage 2007;11:72-81.

35. Wiig K. Knowledge management: an introduction and perspective. J Knowledge Manage 2004;1:6-14.

36. Ackoff RL. From data to wisdom. J Applied Systems Analysis 1989;16:3-9.

37. Klimko G. Knowledge management and maturity models: building common understanding. In: Proceedings of the Second European Conference on Knowledge Management. Bled, Slovenia 2001 Nov 8 (pp. 269-278).

38. Nonaka I. A dynamic theory of organizational knowledge creation. Organizat Sci 1994;5:14-37.

39. Thomas JC, Kellogg WA, Erickson T. The knowledge management puzzle: human and social factors in knowledge management. IBM Systems J 2001;40:863.

40. Bhatt GD. Knowledge management in organizations: examining the interaction between technologies, techniques, and people. J Knowledge Manage 2001;5:68-75.

41. Chiu CM, Hsu MH, Wang ET. Understanding knowledge sharing in virtual communities: an integration of social capital and social cognitive theories. Decision support systems. 2006;42:1872-88.

42. Nahapiet J, Ghoshal S. Social capital, intellectual capital, and the organizational advantage. Acad Manage Rev 1998;23:242-66.

43. Inkpen AC, Tsang EW. Social capital, networks, and knowledge transfer. Acad Manage Rev 2005;30:146-65.

44. Maurer I, Bartsch V, Ebers M. The value of intra-organizational social capital: how it fosters knowledge transfer, innovation performance, and growth. Organiz Studies 2011;32:157-85.

45. Rogers EM. Diffusion of innovations. New York: Free Press; 2003.

46. Bourdieu P, Passeron JC. Reproduction in education, culture and society. Trans Nice R. London: Sage; 1977.

47. Burt RS. Network items and the general social survey. Social networks 1984;6:293-339.

48. Lin N. Building a network theory of social capital. Connections 1999;22:28-51.

49. Portes A. Social capital: its origins and applications in modern sociology. In: Lesser EL. Knowledge and social capital. Boston: Butterworth-Heinemann; 2000. pp 43-67.
50. Putnam RD. Bowling alone: America's declining social capital. J Democracy 1995;6:65-78.

51. Krause J, Croft DP, James R. Social network theory in the behavioural sciences: potential applications. Behav Ecol Sociobiol 2007;62:15-27.

52. Scott J. Social network analysis. Thousand Oaks: Sage; 2012.

53. Otte E, Rousseau R. Social network analysis: a powerful strategy, also for the information sciences. J Informat Sci 2002;28:441-53.

54. Chow WS, Chan LS. Social network, social trust and shared goals in organizational knowledge sharing. Informat Manage 2008;45:458-65.

55. Pereira CS, Soares AL. Improving the quality of collaboration requirements for information management through social network analysis. Int J Informat Manage 2007;27:86-103.

56. Meessen B, Kouanda S, Musango L, et al. Communities of practice: the missing link for knowledge management on implementation issues in low $\square$ income countries? Trop Med Int Health 2011;16:1007-14.

57 Bandura A, Walters RH. Social learning theory. New York: General Learning Press; 1977.

58. Bandura A. Social foundations for thought and action: a social cognitive theory. Englewood Cliffs: Prentice Hall; 1986.

59. Weissmann PF, Branch WT, Gracey CF, et al. Role modeling humanistic behavior: learning bedside manner from the experts. Acad Med 2006;81:661-7.

60. Fox RD, Bennett NL. Learning and change: implications for continuing medical education. Br Med J 1998;316:466.

61. Horvath JA. Tacit knowledge in the professions. In: Sternberg RJ, Horvath JA, eds. Tacit knowledge in professional practice. Mahwah, NJ: Lawrence Erlbaum; 1999. p. ix-xiii.

62. Haynes A, Turner T, Redman S, et al. Developing definitions for a knowledge exchange intervention in health policy and program agencies: reflections on process and value. Int J Soc Res Methodol 2015;18:145-59.

63. Bartunek J, Trullen J, Bonet E, Sauquet A. Sharing and expanding academic and practitioner knowledge in health care. J Health Serv Res Policy 2003;8:62-8.

64 Kahn JG, Yang JS, Kahn JS. Mobile health needs and opportunities in developing countries. Health Affairs 2010;29:252-8.

65. Kamel Boulos MN, Wheeler S. The emerging Web 2.0 social software: an enabling suite of sociable technologies in health and health care education. Health Inform Librar J 2007;24:2-3.

66. Carlile PR. Transferring, translating, and transforming: an integrative framework for managing knowledge across boundaries. Organizat Sci 2004;15:555-68.

67. Yates D, Paquette S. Emergency knowledge management and social media technologies: a case study of the 2010 Haitian earthquake. Int J Informat Manage 2011;31:6-13.

68. Gray K. Public health platforms: an emerging informatics approach to health professional learning and development. J Public Health Research 2016;5.

69. Sedig K, Ola O. The challenge of big data in public health: an opportunity for visual analytics. Online J Public Health Informatics 2014;5.

70. Avram G. At the crossroads of knowledge management and social software. Electron J Knowledge Manage 2006;4:1-10.

71. Zhang Y, Hiltz SR, eds. Factors that influence online relationship development in a knowledge sharing community. Ninth American Conference on Information Systems; 2003.

72. Fricke M. The knowledge pyramid: a critique of the DIKE hierarchy. J Informat Sci 2009;35:131-42. 